$\xi^{2}=-1$

\title{
Soil chemical analysis of gangetic delta plain by combined use of multispectral imagery and XRF spectroscopy
}

\author{
Neha Singh ${ }^{1 *}$, Harshita Asthana ${ }^{2}$, Chandrasekhar Azad Vishwakarma ${ }^{2}$, Ratan Sen $^{2}$, Saumitra Mukherjee ${ }^{2}$ \\ ${ }^{1}$ Corresponding Author; Department of Environmental Studies, The M.S. University of Baroda, Vadodara, Gujarat -390002 \\ ${ }^{2}$ School of Environmental Sciences, Jawaharlal Nehru University, New Delhi-110067 \\ *Corresponding author E-mail: neha8277@gmail.com
}

\begin{abstract}
24 Parganas districts of West Bengal are very well known for their agricultural productivity. These districts are the part of the mature delta plain of the Bengal delta which is formed by the deposition of weathered sediments through Himalayan Rivers. The agricultural productivity of an area depends mainly upon the fertility of soil which in turn depends on the presence of essential nutrients in it. Thus, the present study was carried out to assess the types of minerals present in the soil which provide the elements that act as the nutrients to the plant. Band ratio technique using the Landsat imagery and X-Ray Diffraction was carried out for the study of mineral composition. XRF was done for the elemental composition of the soil samples and Principal Component Analysis was carried out to assess the sources of these nutrients in the soil. Normalized Difference Vegetation Index was also calculated using Landsat imagery to study the vegetation pattern in the area. The study suggests that the area is mainly comprised of clay and ferrous minerals and contains nearly all the elements that act as macro-and micro-nutrients. However, the study also shows the accumulation of some of the heavy metals which may be due to the excessive use of fertilizers.
\end{abstract}

Keywords: Minerals; Weathering; Band Ratio; Nutrients; PCA.

\section{Introduction}

Soil is a complex mixture of weathered mineral materials from rocks, partially decomposed organic matter and a host of living organisms. It is an essential component of the biosphere and interfaces lithosphere, hydrosphere and atmosphere. Soil formation is strongly influenced by the parent material, climate and living organisms acting on it, topography and time. For the proper growth, a plant requires 16 essential elements of which carbon, hydrogen and oxygen are derived from air and water and the rest of the essential elements come from the soil in the form of the inorganic salts. Nitrogen $(\mathrm{N})$, phosphorus $(\mathrm{P})$, potassium $(\mathrm{K})$, calcium $(\mathrm{Ca})$, magnesium $(\mathrm{Mg})$ and sulphur $(\mathrm{S})$ are the macronutrients, while boron $(\mathrm{B})$, chlorine $(\mathrm{Cl})$, copper $(\mathrm{Cu})$, iron $(\mathrm{Fe})$, manganese $(\mathrm{Mn})$, molybdenum (Mo) and zinc ( $\mathrm{Zn})$ are the micronutrients. Micronutrients or trace elements are the nutrients which are required in very small quantities, but are very important to the plants. Due to increased use of high analysis fertilizers, high yielding crop varieties and increase in cropping intensity, deficiency of major plant nutrients as well as micronutrients has increased over the last three decades both in magnitude and extent. The deficiency of nutrients has become the major constraint to stability, productivity and sustainability of soils (Bell \& Dell 2008). The sustainable productivity of an agro-ecosystem depends mainly on the soil, which in turn depends on its ability to supply the essential nutrients to the growing plants.

Physico-chemical properties of soil like soil texture, organic carbon, cation exchange capacity, $\mathrm{pH}$ and electrical conductivity of soil influence the plant growth and the crop yield by controlling the availability of nutrients to the plant (Bell \& Dell 2008). Contents of nutrients in the soil and their availability to plants are assessed by the mineral present and their weathering processes. The soil plays an important role in the accumulation or mobilization of heavy metals in the hydrologic cycle or ecosystems (Vernet 1992; Huang 1998). Natural sources of heavy metals in the soil are the weathering of the rock mineral, and the concentration depends on the element abundance in the parent material. Anthropogenic sources are hazardous/solid waste disposal, the combustion process in industry and transportation, mining activities for the extraction of metallic products, and agricultural activities. The concentration of heavy metal is normally below the toxic concentration but during pedogenesis and biocycling, the transformation of heavy metals can affect their chemical speciation and bioavailability. Distribution of heavy metal can be affected by the soil physical and chemical properties like redox conditions, $\mathrm{pH}$ and water content (Wolt 1994).

Application of remote sensing has been increased in the mineral exploration and geological mapping. Near-infrared, mid-infrared, and shortwave infrared electromagnetic windows are very helpful in the geological analysis through remote sensing. VNIR bands were first used to derive the iron oxide ratio images by the band ratio technique in Landsat multispectral scanner (Goetz \& Rowan 1981). With the advent of Landsat Thematic Mapper (TM), the application of remote sensing in geology has accelerated for mapping of lithology, delineation of lineaments, and map alteration mineralogy. The Landsat TM Band 5/band 7 ratios reflect the presence or absence of hydroxyl absorption bands, while band 5/band 4 and band 3/band 1 indicate the $\mathrm{Fe}-\mathrm{O}$ or non Fe-O materials (Meer et al. 2012). Crosta and Moore (1989) and Ferrier et al. (2002) used band 5 and band 7 of Landsat thematic mapper in discriminating different rock types and identification of hydrothermal alterations. In the present study, band ratio was calculated for the area to see the abundance of ferrous or clay 
minerals and finally mineral composite map was prepared. The sub-surface soil samples collected from the study area were analysed for mineral and elemental composition and principal component analysis was applied to the data to study for the essential minerals for the plants.

\section{Methodology}

\subsection{Study area}

31 soil samples were collected during the study from a depth ranging from $20-50 \mathrm{~cm}$ and were stored in the polypropylene bags. The latitude and longitude of the sampling points were noted with Garmin GPS, and points have been shown in Fig 1. Soil samples were collected from the open fields with the help of auger after removing few layers of the surface soil, and the samples were then sealed tightly with cello tape to retain the moisture intact into the soil. The samples were collected from the selected sites of the area in North 24 Parganas and South 24 Parganas districts of West Bengal. The North 24 Parganas and South 24 Parganas districts are located in the lower deltaic plain of composites Gangetic delta Area is covered by the Quaternary sediments deposited by river and its tributaries. The major soil types in the study area are Younger and Older alluvial soils and Lateritic soil. Proportion of agricultural land in West Bengal is the highest among all the
Indian states. Agriculture is the main source of livelihood; rice, sugarcane, timber and betel nuts are the principal agricultural products. Rice is the major crop in all the parts of the West Bengal, while jute is grown prominently along the border with Bangladesh and in the south of the Ganges river.

\subsection{Band ratio}

Band ratio is calculated by dividing the digital number of each pixel in one band by the digital number of pixels in another band which acts as the denominator (Mshiu 2011). The contrast between objects can be enhanced by dividing the brightness values pixel by pixel of one by another band. Band ratioing is widely used to explore the mineral by enhancing the spectral feature of the alteration zones that depend on the absorption bands of their altered minerals (Khidir \& Babikir 2013). Band ratio was calculated using clay mineral, ferrous minerals and iron oxide indices in Erdas Imagine Software (Sabins 1987; Jensen 1996; Campbell 1996). Landsat TM image for year 2009 was used to calculate the indices. Clay/hydroxyl minerals have a high reflectance in band 5 and absorption of radiation in band 7 (Darning 1998). Band ratio 5/4 and 3/1 are used to illuminate the ferrous and ferric oxide

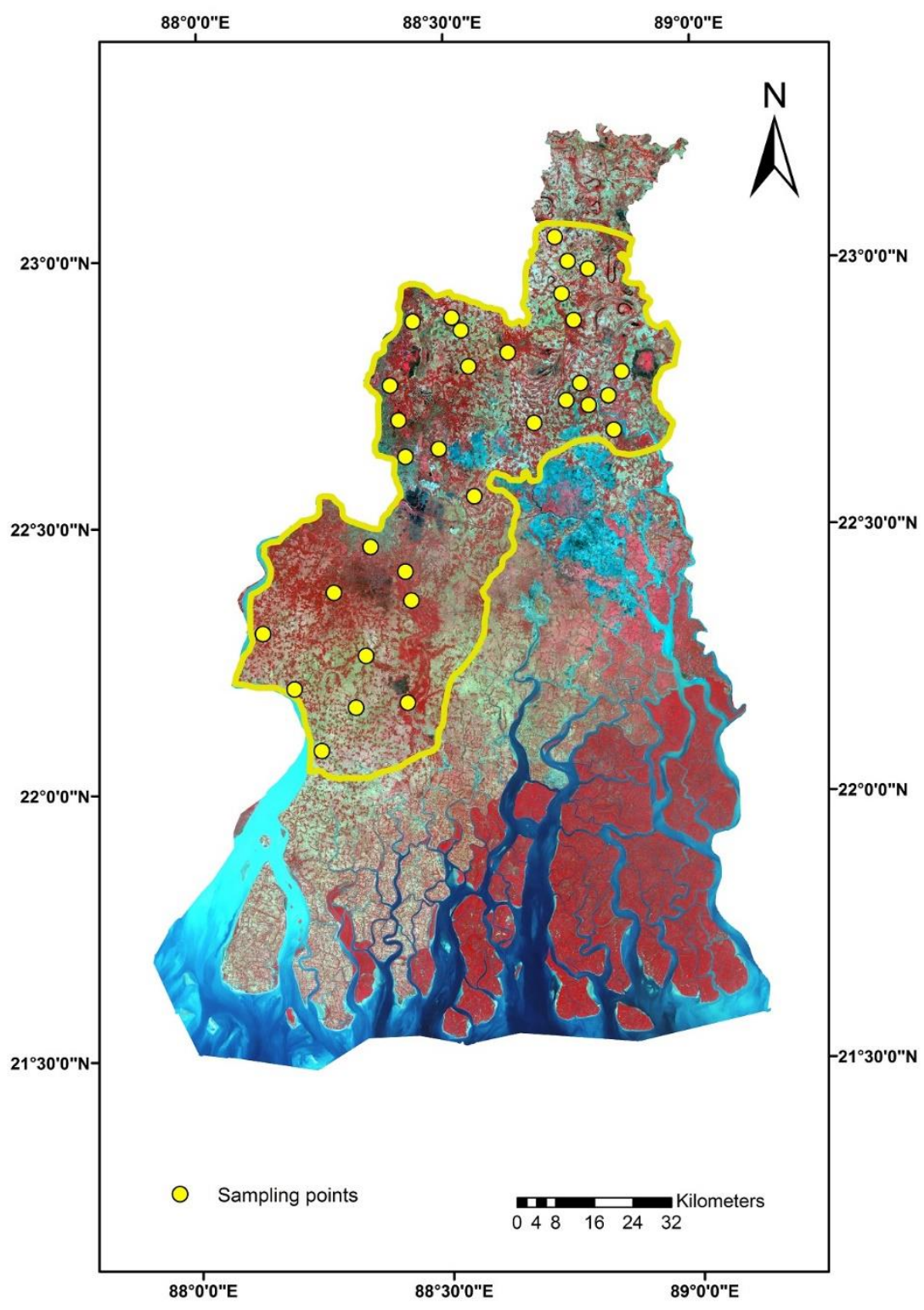

Fig. 1: Soil Sampling Points Shown in the Landsat Image. 
Minerals, while band ratio 5/7 is used to detect the high values of the clay and hydroxyl bearing minerals like kaolinite, illunite, muscovite, epidotes, chlorites and amphiboles (Gupta 2003). The mineral composite term is used to express the group of minerals that consists of clay minerals, ferrous minerals, and iron oxides. Sabin's ratio $($ Red $=$ Band $5 /$ Band 7 , Green $=$ Band $5 /$ Band 4 , Blue $=$ Band $3 /$ Band 1) was used to produce a false colour composite image for the mineral composite.

\subsection{XRD}

To validate the result obtained from the band ratioing, mineral identification was done through X-ray diffraction study of the soil. Samples of grain size less than $45 \mu$ were used for the XRD analysis of the soil samples. Each sample is subjected to monochromatic radiation of X-rays generated by a cathode ray tube. The monochromatic beam is scattered by the atoms present in the mineral, and interaction of incident rays with the sample produce constructive interference (diffracted ray). The wavelength of electromagnetic radiation is related to the diffraction angle and the lattice spacing in crystalline sample with the Bragg's equation.

$\mathrm{n} \lambda=2 \mathrm{~d} \sin \theta$

Due to random orientation of the powdered sample, all possible diffraction direction is checked by scanning the sample through a range of $2 \Theta$ angles and counting the diffracted X-rays. As each mineral has a set of unique $d$-spacing, identification of the minerals can be achieved by converting the diffraction peaks to dspacing and comparing with standard reference patterns.

\subsection{XRF}

X-ray Fluorescence spectrometry is an analytical technique to analyze the elemental composition by the excitation of atoms and detection of characteristic X-rays. X-ray fluorescence spectrometer (Pan Analytical) was used to analyze the soil samples of size less than $45 \mu$. For XRF analysis, $0.2 \mathrm{~g}$ of boric acid powder was mixed with $2 \mathrm{~g}$ of dried soil and was grinded in mortar and pestle to form a homogeneous mixture. In a semiautonomous press (Insmart system), under 12 tonnes of pressure, pellets were prepared by pressing the samples for one minute. After pellet preparation, samples were analyzed in Wavelength Dispersive - XRF and Energy Dispersive - XRF. ED-XRF detects a group of elements all at once while WD-XRF has very high resolution with fewer spectral overlaps, thus more accurate results.

\subsection{NDVI}

The Normalised Difference Vegetation Index is an index based on spectral reflectance of ground surface features. The normalized difference vegetation index is derived by dividing the difference between infrared and red reflectance measurements by their sum which provides the effective measure of photosynthetic active biomass (Coppin et al. 2004; Lunetta et al. 2006).

NDVI $=\frac{\text { NIR-RED }}{\text { NIR+RED }}$

The Normalized Difference Vegetation Index (NDVI) derived from visible/near infrared satellite data is a valuable method to estimate vegetation health. NDVI value ranges between -1 to +1 . Higher value of NDVI infers the presence of healthy vegetation in the area while its lower value is the indicator of sparse vegetation. Landsat TM image (year 2009) was used to calculate the NDVI for analyzing the vegetation pattern in the area.

\section{Results and discussion}

\subsection{Mineral composition}

\section{a) Through Band Ratioing}

Ratioing technique not only evaluates the spectral properties of earth materials by revealing the reflectance differences between bands, but also minimizes the brightness variations due to albedo and topographic slope (Rowan \& Lathram 1980). Surface conditions like vegetation, agricultural activities, and weathering crust act as a barrier in the mineral exploration, and may cause hindrance in the interpretation of geological and structural signals (Drury 1993). Clay minerals have distinctive reflectance minima at the wavelength within the range of TM band 7 because of the absorption caused by the minerals, while higher reflectance values within TM band 5. Thus, the band 5/7 ratio for the place having clay minerals is much greater than unity. Fig 2 is the ratio image of band $5 /$ band 7; the image has been given the stretch of brown colour where lighter shade of brown shows minimum values and darker shade the maximum. The highest value of band 5/7 ratio is 4.33. The image shows the higher clay deposits in the southwestern part of the study area. Ratio of TM Band 5/ Band 4 highlights the presence of iron bearing minerals. Fig 3 shows the area which has ferrous minerals in abundance. The highest ratio of ferrous mineral indices calculated through ratio of band $5 / 4$ is 3.04 , and is dominant in the southern and central part of the study area.

TM band 3/band1 ratio image highlights the minerals that have been subjected to oxidation of iron bearing sulphides. In the ratio image, higher values will represent the areas of more intense iron sulphide oxidation. The study area does not have iron sulphide oxidation as the highest ratio of iron oxide indices was 1.03 (Fig 4) approximately equal to unity. This shows that the study area has clay and ferrous minerals, but very minimal iron oxide minerals. Colour composite image was created by placing the clay indices in red, ferrous indices in green, and iron oxide band ratio in green. This FCC image shows the spatial distribution pattern of both the clay and the iron minerals (Fig 5). 


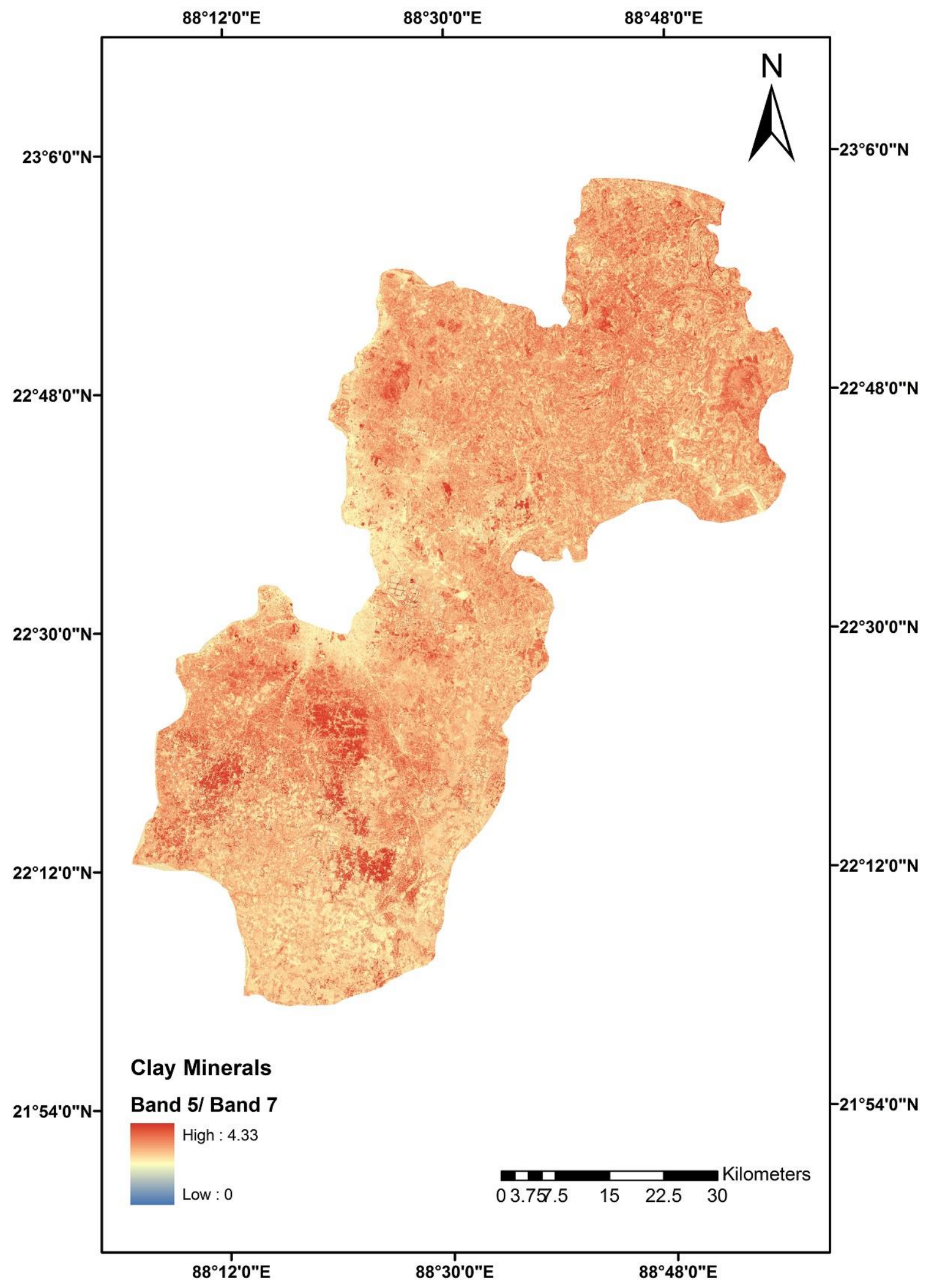

Fig. 2: Band Ratio Image for Clay Indices. 


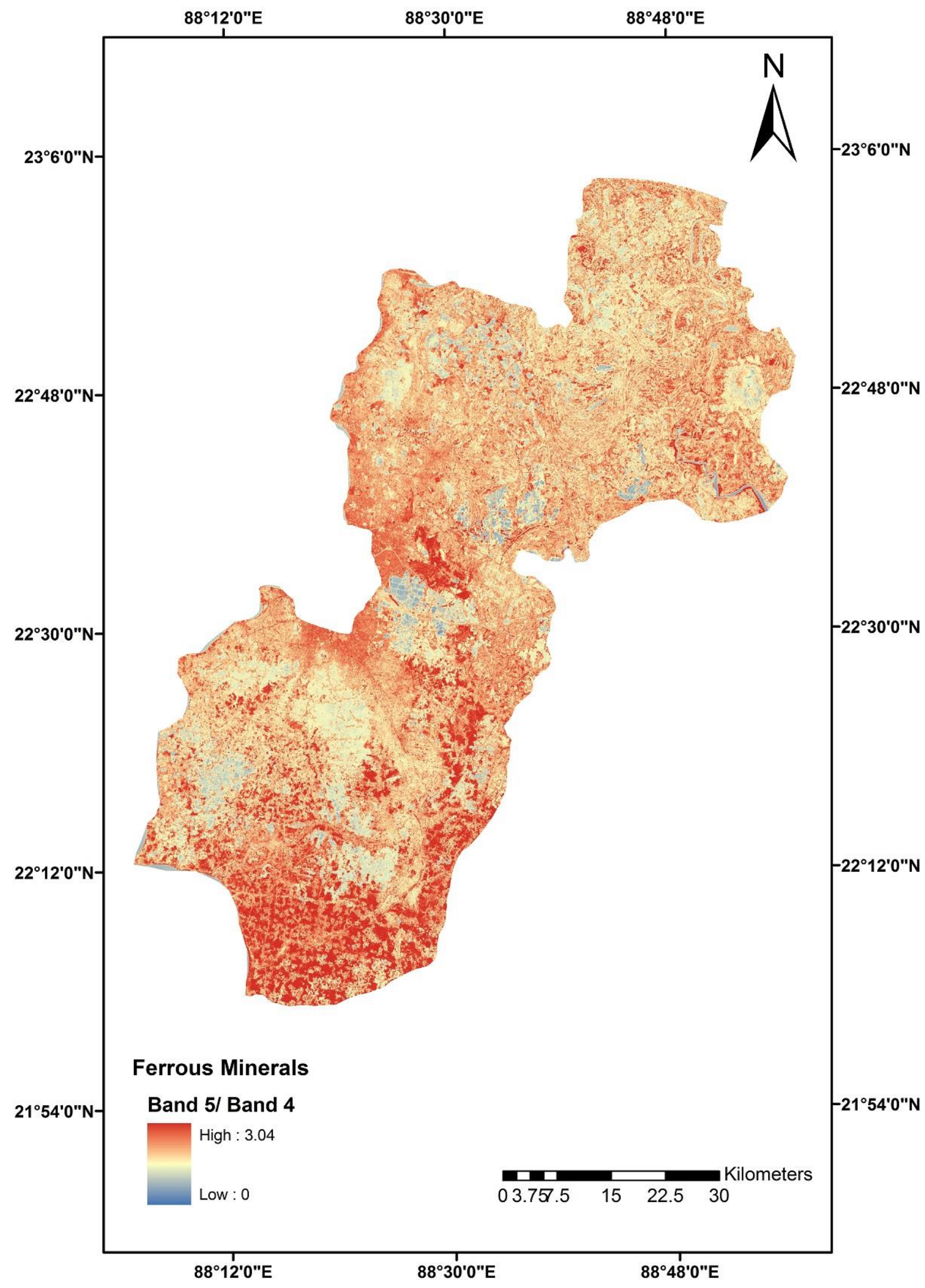

Fig. 3: Band Ratio Image for Ferrous Minerals. 


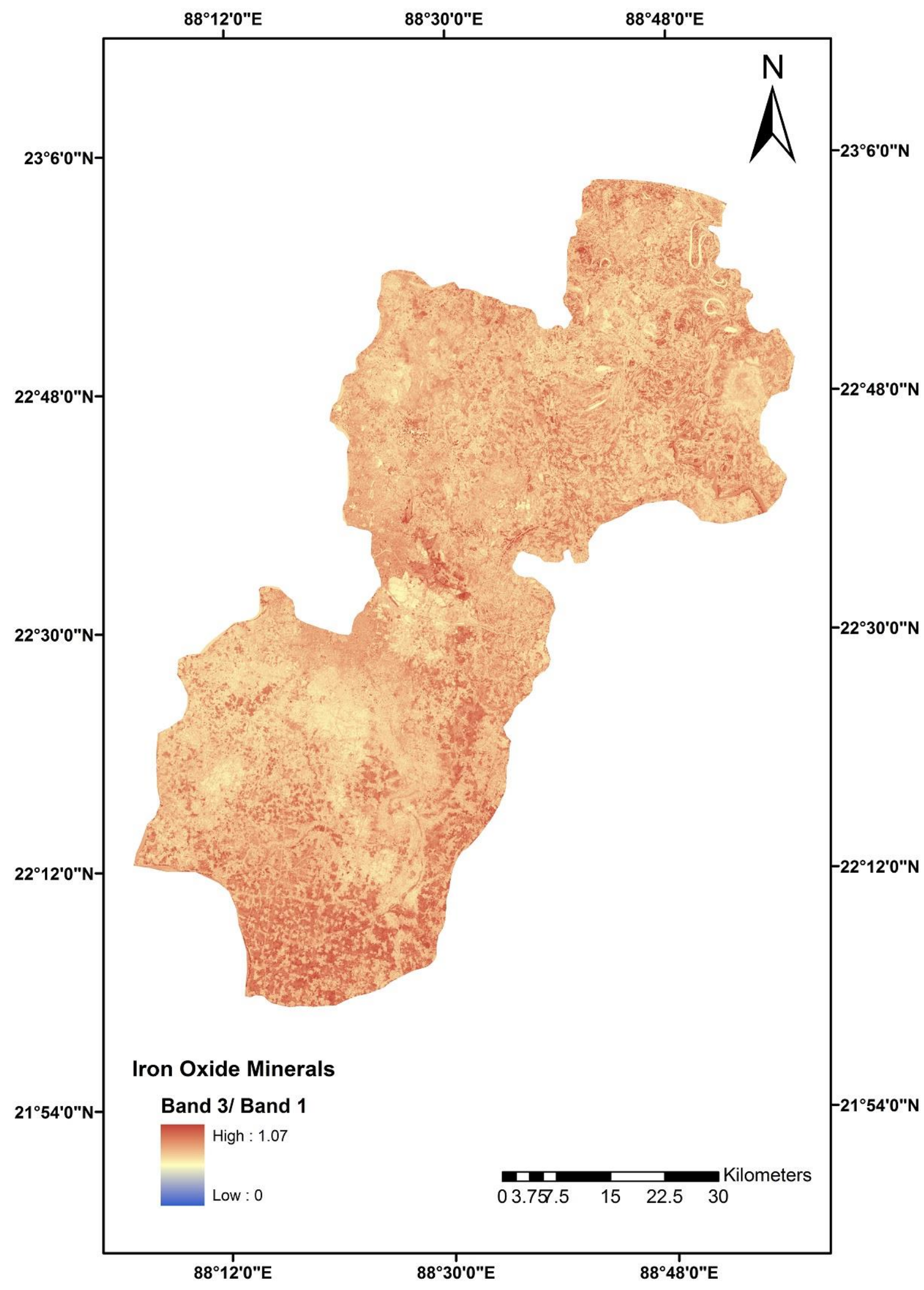

Fig. 4: Band Ration Image for Iron Oxide Minerals. 


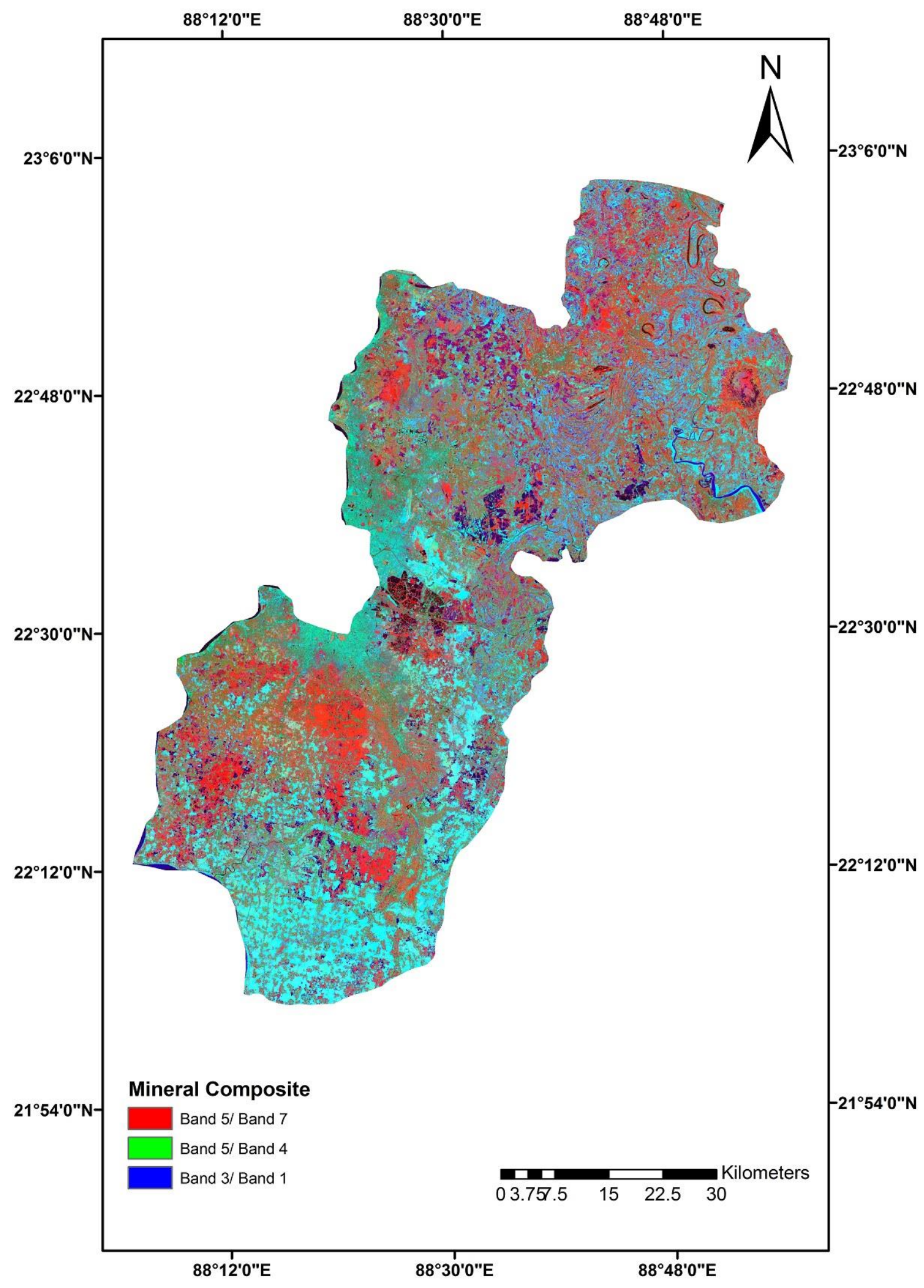

Fig. 5: Colour Composite Image for Clay and Iron Minerals. 
b) XRD analysis

Heavy mineral assemblages reported for North 24 Parganas are kyanite-garnet-staurolite-biotite-tourmaline-chlorite-hornblendeepidote in light grey micaceous fine to medium sand and stauroloite-garnet-sillimanite-opaque tourmaline-kyanite-biotite-chlorideepidote in the reddish brown sand (Elangovan \& Chalakh 2006). Fig 6 shows the XRD pattern in one of the soil samples. XRD analysis gives the qualitative composition of the soil samples. The most frequent components and common in all the soil samples are quartz, albite, augite, diopside, muscovite. Besides these, samples showed the presence of minerals like orthoclase/oligoclase, anhydrite, kyanite, microcline, calcite, epidote, dolomite and siderite.

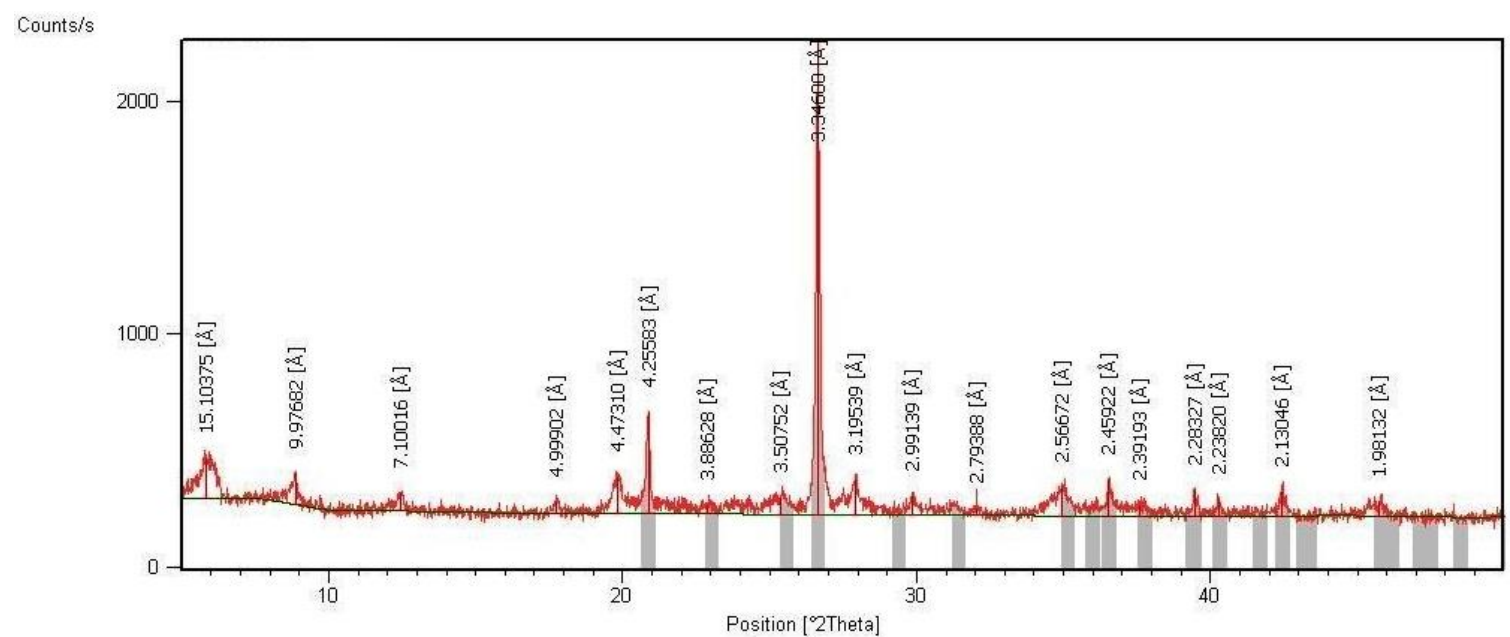

Fig. 6: XRD Pattern in Soil Sample Showing D-Spacing.

\subsection{Elemental composition}

a) XRF analysis

$\mathrm{XRF}$ results of the collected soil samples show the presence of following elements into the soil- $\mathrm{Na}, \mathrm{K}, \mathrm{Ca}, \mathrm{Mg}, \mathrm{Al}, \mathrm{Si}, \mathrm{P}, \mathrm{S}, \mathrm{Cl}$ $\mathrm{Mn}, \mathrm{Fe}, \mathrm{Ni}, \mathrm{Cu}, \mathrm{Zn}, \mathrm{Ga}, \mathrm{As}, \mathrm{Cr}, \mathrm{V}, \mathrm{Ti}, \mathrm{Rb}, \mathrm{Sr}, \mathrm{Y}, \mathrm{Zr}, \mathrm{Nb}, \mathrm{Ba}, \mathrm{La}$ $\mathrm{Ce}, \mathrm{Nd}, \mathrm{W}, \mathrm{Pb}$. Some of the elements belong to alkali and alkaline earth metals, some to the heavy metals group, and some to rare earth elements. In the present study, rare earth and transition elements have not been considered. Chromium concentration has been reported in 3-4 samples only, thus in the further study this element also has not been considered. Though there is the presence of several heavy metals in the surface soil besides alkali and alkaline earth metals in the study area, a different approach has been taken to analyse the elemental composition. Further analysis targeted the nutrients that are available in the soil for the plant growth, as the 24 Parganas districts are known for the agricultural productivity. Though the total quantity of nutrients in soil is not the indicator of its availability to plants (McLaren et al. 1984), the study has been focussed on the elements available in the soil, which act as the nutrients to the plant. Along with the essential components, $\mathrm{Ni}, \mathrm{Al}, \mathrm{Pb}$ and $\mathrm{As}$ have also been considered.

Table 1 shows the concentration of elements analysed through $\mathrm{XRF}$ in the soil sample. All the concentrations are in ppm. Potassium, calcium, magnesium, silica, iron and aluminium are present in very high concentration. Besides these, all the essential elements except molybdenum are present in the soil sample. To simplify the result of the XRF, Principal Component Analysis was performed to reduce the dataset into some variables which help in the deduction of important parameters.

b) Principal component analysis

Principal Component Analysis is a multivariate statistical technique which is used for the reduction of data set by deciphering the pattern within. It reduces the large data set of variables into few factors (the principal components) which are orthogonal (uncorrelated) and their interpretation reveals underlying data structure. PC1 account for the maximum possible proportion of the total variance in the data set and PC2 gives the maximum value for the total remaining variance and so on. As per the Kaiser criterion, principal components having the Eigenvalue greater than one are essential and explain the total variance in the data set (Cattell \& Jaspers 1967). Loading of the principal component explains the relationship (positive or negative) between the variables and the factor, but the use of varimax rotation in principal component analysis can reduce the overlapping of the original variables. Varimax rotation maximises the relationship between variables and some factors by rotating the factor loading matrix, which results in high factor loading for the variables correlated in the factor and low values for the remaining variables.

In the present study, PCA has reduced the data sets from 16 variables to 5 components that explain $80.182 \%$ of the total variance (Table 2). In the interpretation of dataset, components that load more than 0.6 have been taken into the consideration (Mazlum et al. 1996). PC1 which accounts for the $35.022 \%$ of the total variance has the highest positive loading of $\mathrm{Mg}, \mathrm{Al}, \mathrm{K}, \mathrm{Fe}$, $\mathrm{Ni}$, and higher negative loading of Si (Table 3). Loading of these elements on PC1 indicates the common sources of these elements. The natural mineral assemblage of the area and the weathering processes may be the source of the abundance of these ions in the soil. Heavy metals like $\mathrm{Ni}, \mathrm{Cr}$, and $\mathrm{Mn}$ are found as trace elements in rock types of volcanic and metamorphic origin (Alloway 1995a). PC2 which accounts for the $18.129 \%$ of the variance shows the positive loading for the $\mathrm{P}, \mathrm{Cu}, \mathrm{Zn}$ and $\mathrm{Pb}$. $\mathrm{PC} 2$ accounts for the anthropogenic input of these elements into the soil. Frequent application of pesticides in the agricultural land may lead to accumulation of heavy metals such as copper, zinc and cadmium in the topsoil (Mortvedt 1996). Holmgrem et al. (1993) studies have shown that zinc and copper get accumulated in the top soils from normal agricultural practices. High loading of $\mathrm{Pb}$ may be due to deposition of vehicular emissions. 
Table 1: Chemical Analysis of the Soil Samples (ppm)

\begin{tabular}{|c|c|c|c|c|c|c|c|c|}
\hline S.No & $\mathrm{Na}$ & $\mathrm{K}$ & $\mathrm{Ca}$ & $\mathrm{Mg}$ & $\mathrm{P}$ & S & $\mathrm{Si}$ & $\mathrm{Cl}$ \\
\hline 1 & 6943.81 & 19417.44 & 12128.46 & 13394.85 & 662.33 & 398.16 & 328320.51 & 527.06 \\
\hline 2 & 5044.65 & 23784.08 & 13822.30 & 16313.86 & 960.12 & 220.44 & 319541.98 & 450.60 \\
\hline 3 & 6558.04 & 23551.64 & 7554.38 & 14757.86 & 0.00 & 502.81 & 314316.00 & 342.95 \\
\hline 4 & 0.00 & 22937.32 & 28780.97 & 15517.76 & 0.00 & 0.00 & 321379.02 & 191.39 \\
\hline 5 & 6031.32 & 24091.24 & 15430.37 & 14739.76 & 755.63 & 1181.45 & 315447.21 & 604.18 \\
\hline 6 & 7656.00 & 19832.52 & 9569.83 & 11133.23 & 137.91 & 199.59 & 350135.93 & 202.25 \\
\hline 7 & 7707.93 & 23161.46 & 14329.74 & 13521.50 & 0.00 & 343.66 & 334303.74 & 177.11 \\
\hline 8 & 9799.97 & 23867.10 & 14344.03 & 13708.46 & 885.93 & 135.31 & 332583.56 & 4870.00 \\
\hline 9 & 6721.25 & 22173.57 & 16845.48 & 15107.66 & 445.40 & 841.03 & 334472.02 & 96.46 \\
\hline 10 & 7492.79 & 25801.37 & 4538.35 & 12037.88 & 0.00 & 148.87 & 335276.01 & 252.26 \\
\hline 11 & 7834.04 & 22987.13 & 9426.89 & 14269.35 & 0.00 & 0.00 & 325889.82 & 2600.00 \\
\hline 12 & 0.00 & 26249.66 & 8204.76 & 14492.49 & 0.00 & 213.10 & 326385.31 & 1407.41 \\
\hline 13 & 7255.39 & 22107.16 & 22834.67 & 14046.20 & 0.00 & 5130.28 & 331788.91 & 266.77 \\
\hline 14 & 5749.42 & 22929.02 & 15373.20 & 11796.64 & 1213.25 & 578.70 & 338085.33 & 141.15 \\
\hline 15 & 5393.32 & 24157.66 & 15137.35 & 14582.96 & 1139.06 & 973.19 & 309393.86 & 1312.78 \\
\hline 16 & 0.00 & 20181.19 & 14972.97 & 12393.71 & 4412.21 & 572.62 & 335145.13 & 561.61 \\
\hline 17 & 6498.69 & 24124.45 & 17531.59 & 14486.46 & 1745.68 & 0.00 & 330498.78 & 0.00 \\
\hline 18 & 8865.23 & 21318.51 & 34948.83 & 13780.84 & 0.00 & 0.00 & 328759.90 & 387.73 \\
\hline 19 & 3939.28 & 22115.46 & 13193.36 & 12610.82 & 705.72 & 0.00 & 345704.60 & 0.00 \\
\hline 20 & 6046.16 & 23003.73 & 12607.31 & 12526.39 & 1754.41 & 981.20 & 329914.48 & 233.18 \\
\hline 21 & 8635.25 & 21716.99 & 34877.36 & 15119.72 & 677.95 & 2599.18 & 304869.04 & 885.05 \\
\hline 22 & 0.00 & 25950.80 & 5803.36 & 15632.35 & 0.00 & 5222.39 & 320434.79 & 2230.00 \\
\hline 23 & 6046.16 & 25842.88 & 7239.91 & 13382.79 & 0.00 & 162.99 & 330124.83 & 488.35 \\
\hline 24 & 7299.90 & 21351.72 & 10491.80 & 9130.93 & 633.34 & 792.45 & 352982.64 & 48.45 \\
\hline 25 & 5971.97 & 22870.91 & 8376.28 & 11253.85 & 1160.88 & 280.44 & 349617.07 & 136.88 \\
\hline 26 & 0.00 & 23493.53 & 20311.77 & 15354.93 & 0.00 & 526.39 & 316480.25 & 230.63 \\
\hline 27 & 7136.69 & 21177.38 & 7368.56 & 12339.43 & 0.00 & 278.88 & 348855.15 & 236.37 \\
\hline 28 & 6862.21 & 23269.38 & 11163.61 & 13322.48 & 0.00 & 0.00 & 338393.84 & 0.00 \\
\hline 29 & 6869.62 & 22904.11 & 9677.04 & 12870.15 & 514.89 & 294.23 & 341483.62 & 81.39 \\
\hline 30 & 5645.55 & 24481.42 & 8576.40 & 14468.37 & 759.05 & 681.64 & 330265.06 & 143.90 \\
\hline 31 & 2069.79 & 26316.07 & 7161.29 & 16319.89 & 0.00 & 162.79 & 303550.86 & 135.45 \\
\hline
\end{tabular}

Table 1: (Continued)

\begin{tabular}{|c|c|c|c|c|c|c|c|c|}
\hline S.No & $\mathrm{Cu}$ & $\mathrm{Fe}$ & $\mathrm{Mn}$ & $\mathrm{Zn}$ & $\mathrm{Ni}$ & $\mathrm{Al}$ & $\mathrm{Pb}$ & As \\
\hline 1 & 45.84 & 40769.77 & 770.88 & 98.56 & 27.69 & 81319.26 & 39.27 & 2.95 \\
\hline 2 & 53.80 & 36356.37 & 786.65 & 69.69 & 32.39 & 88977.51 & 33.02 & 2.95 \\
\hline 3 & 53.28 & 41986.78 & 1005.92 & 91.71 & 34.38 & 95963.61 & 52.07 & 0.75 \\
\hline 4 & 49.51 & 35768.85 & 1100.69 & 56.44 & 30.48 & 82547.12 & 28.77 & 7.66 \\
\hline 5 & 79.33 & 43574.49 & 573.28 & 197.71 & 35.43 & 85833.77 & 68.45 & 5.93 \\
\hline 6 & 40.20 & 25396.30 & 831.24 & 54.04 & 16.77 & 69464.06 & 30.58 & 1.51 \\
\hline 7 & 33.90 & 30425.21 & 987.56 & 75.63 & 24.34 & 78852.96 & 30.45 & 4.28 \\
\hline 8 & 39.36 & 28914.44 & 824.40 & 62.97 & 24.53 & 76381.36 & 32.09 & 0.00 \\
\hline 9 & 30.29 & 32285.69 & 534.10 & 86.70 & 23.95 & 74407.26 & 26.73 & 4.90 \\
\hline 10 & 27.03 & 34349.01 & 724.31 & 53.04 & 26.07 & 82234.87 & 26.43 & 4.95 \\
\hline 11 & 52.24 & 34929.53 & 425.64 & 65.73 & 25.52 & 86886.97 & 22.12 & 6.30 \\
\hline 12 & 39.21 & 38503.62 & 899.95 & 70.40 & 31.26 & 88077.79 & 31.15 & 4.69 \\
\hline 13 & 33.57 & 27508.58 & 792.18 & 153.51 & 17.52 & 72163.24 & 26.66 & 4.27 \\
\hline 14 & 46.53 & 30194.39 & 776.39 & 110.32 & 22.30 & 75042.36 & 52.20 & 1.38 \\
\hline 15 & 92.51 & 41958.81 & 985.07 & 192.85 & 39.33 & 93804.27 & 79.46 & 0.00 \\
\hline 16 & 71.22 & 29271.15 & 1061.35 & 158.47 & 31.78 & 79551.57 & 38.80 & 4.26 \\
\hline 17 & 49.49 & 33985.30 & 973.51 & 69.41 & 28.70 & 75624.53 & 27.50 & 6.64 \\
\hline 18 & 35.76 & 29124.27 & 741.70 & 47.95 & 15.80 & 70803.07 & 27.08 & 5.47 \\
\hline 19 & 37.89 & 28921.43 & 790.89 & 55.03 & 18.24 & 71612.82 & 26.70 & 2.97 \\
\hline 20 & 54.97 & 34279.06 & 873.08 & 214.32 & 27.68 & 80403.66 & 46.76 & 4.43 \\
\hline 21 & 64.48 & 43140.84 & 1119.26 & 275.16 & 33.09 & 80657.70 & 61.65 & 4.46 \\
\hline 22 & 36.16 & 39986.41 & 750.59 & 66.30 & 26.12 & 87987.81 & 30.83 & 3.43 \\
\hline 23 & 38.51 & 35174.33 & 856.04 & 166.02 & 26.57 & 84833.48 & 31.79 & 3.58 \\
\hline 24 & 34.26 & 25158.50 & 663.81 & 183.76 & 17.59 & 68966.57 & 33.36 & 1.39 \\
\hline 25 & 40.30 & 26893.08 & 799.53 & 69.24 & 19.04 & 70713.09 & 36.03 & 1.91 \\
\hline 26 & 59.83 & 40063.35 & 1152.60 & 114.51 & 33.18 & 90004.26 & 50.89 & 4.87 \\
\hline 27 & 29.36 & 26151.69 & 568.96 & 42.25 & 18.82 & 73385.81 & 26.16 & 2.69 \\
\hline 28 & 36.87 & 30970.76 & 648.94 & 51.04 & 23.00 & 77805.04 & 26.25 & 6.19 \\
\hline 29 & 39.27 & 30271.33 & 721.25 & 62.14 & 14.27 & 74566.03 & 42.15 & 0.12 \\
\hline 30 & 49.35 & 36678.11 & 900.91 & 88.98 & 28.97 & 80795.31 & 40.41 & 1.79 \\
\hline 31 & 68.62 & 53149.69 & 1332.32 & 83.01 & 45.46 & 100435.77 & 46.42 & 3.30 \\
\hline
\end{tabular}


Table 2: Principal Component Extracted and Total Variance Explained

\begin{tabular}{|c|c|c|c|c|c|c|}
\hline \multirow{2}{*}{ Component } & \multicolumn{3}{|c|}{ Initial Eigenvalues } & \multicolumn{3}{|c|}{ Rotation Sums of Squared Loadings } \\
\hline & Total & $\%$ of Variance & Cumulative $\%$ & Total & $\%$ of Variance & Cumulative $\%$ \\
\hline 1 & 6.186 & 38.663 & 38.663 & 5.604 & 35.022 & 35.022 \\
\hline 2 & 2.456 & 15.353 & 54.016 & 2.901 & 18.129 & 53.151 \\
\hline 3 & 1.736 & 10.851 & 64.867 & 1.739 & 10.870 & 64.021 \\
\hline 4 & 1.444 & 9.026 & 73.894 & 1.371 & 8.570 & 72.591 \\
\hline 5 & 1.006 & 6.288 & 80.182 & 1.214 & 7.591 & 80.182 \\
\hline 6 & .962 & 6.010 & 86.191 & & & \\
\hline 7 & .750 & 4.690 & 90.881 & & & \\
\hline 8 & .478 & 2.987 & 93.868 & & & \\
\hline 9 & .304 & 1.897 & 95.766 & & & \\
\hline 10 & .284 & 1.776 & 97.542 & & & \\
\hline 11 & .154 & .965 & 98.507 & & & \\
\hline 12 & .091 & .569 & 99.076 & & & \\
\hline 13 & .061 & .379 & 99.455 & & & \\
\hline 14 & .047 & .296 & 99.751 & & & \\
\hline 15 & .039 & .244 & 99.996 & & & \\
\hline 16 & .001 & .004 & 100.000 & & & \\
\hline
\end{tabular}

Table 3: Rotated Component Matrix for the Loading of Principal Components

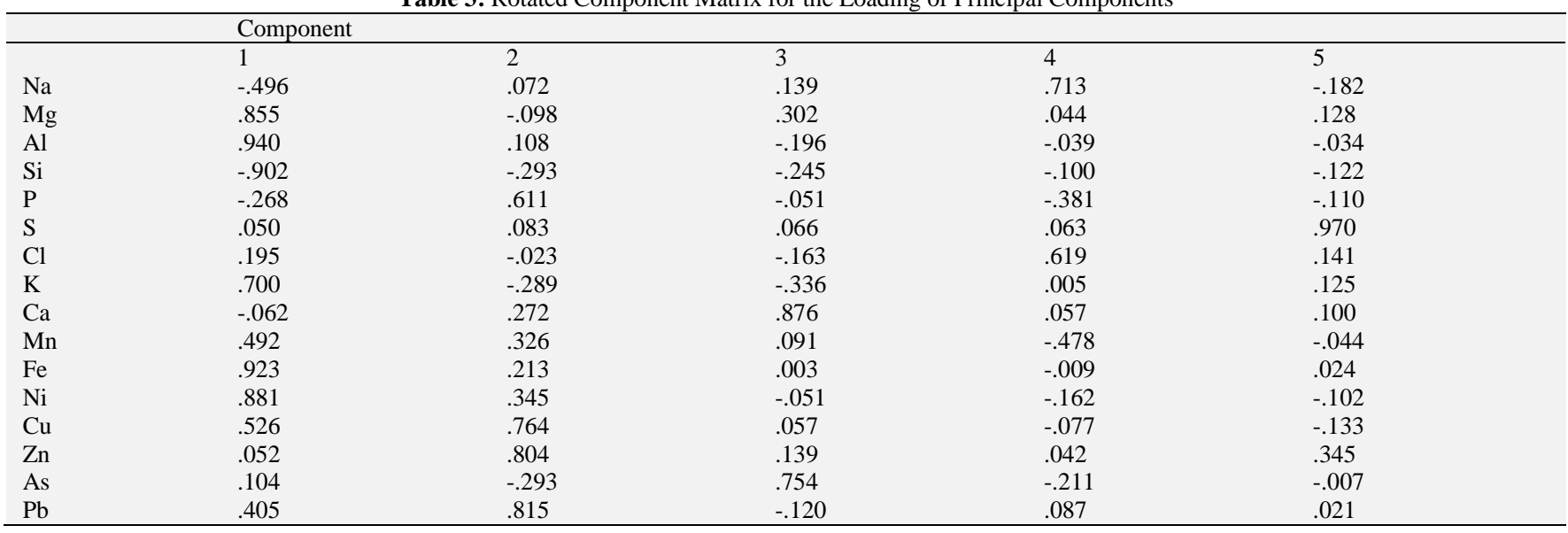

PC3 shows the positive loading for the $\mathrm{Ca}$ and As and explains $10.87 \%$ of the total variance. PC4 accounts for the $8.57 \%$ of the variance and shows the positive loading for the sodium and chloride. PC5 contributes to $7.591 \%$ of the total variance and has the positive loading for the sulphur. Under acidic condition $\mathrm{Ni}, \mathrm{Cu}$ and $\mathrm{Zn}$ have high mobility under the acidic condition, and under reducing condition due to formation of sparingly soluble metal sulphides with very low mobility, these metals can be enriched or depleted relative to the parent rock depending on the weathering environment (Mattigod \& Page 1983).

Albite is sodium-aluminium silicate; augite is single chain inosilicate with calcium, sodium, magnesium, iron, and aluminium; muscovite is potassium aluminium silicate; kyanite is aluminium silicate; microcline is potassium-rich alkali feldspar; epidote is calcium, iron, aluminium silicate. The mineral assemblage of the region is mainly silicate group and explains the high concentration and intercorrelation of $\mathrm{Mg}, \mathrm{Al}, \mathrm{K}, \mathrm{Fe}, \mathrm{Ni}$, and $\mathrm{Si}$ in the result. Clay minerals, a group of hydrous aluminium silicates, play a very important role in the chemical reaction in the soil. Clay minerals can hold moisture and plant nutrient elements (Akalan 1977), also influence the movement and retention of contaminants, metals and nutrients (Grim 1962), thus very important for the agriculture (Moore \& Reynolds 1997). Clay minerals are generally composed of phyllosilicate minerals having the variable amount of water trapped in its structure.

\subsection{NDVI analysis}

The Normalized Difference Vegetation Index is a very useful index to identify the green plant canopies of the study area using multispectral remote sensing data. The NDVI values range from -1 to +1 , where non-vegetated area has NDVI value of 0 or less than 0 , while a value of 0 to 1 indicate a wide variety of vegetation from the bare surface of dense forest. In the study area, the NDVI value ranges from -0.45 to 0.67 (Fig 7). The NDVI image of the area has been given the stretched colour of green where negative to 0 values are shown in brown and lighter shades. The increase in the value of NDVI has been shown in increasing shades of green in the map. The legend shows the variation of colour for the NDVI values in the study area. Though the highest value of NDVI is only 0.67 , but most part of the area comes under the vegetated region, this is because the area is mainly agricultural land. The cropping pattern, density and health of cropped plant determine the NDVI values in the study area. 


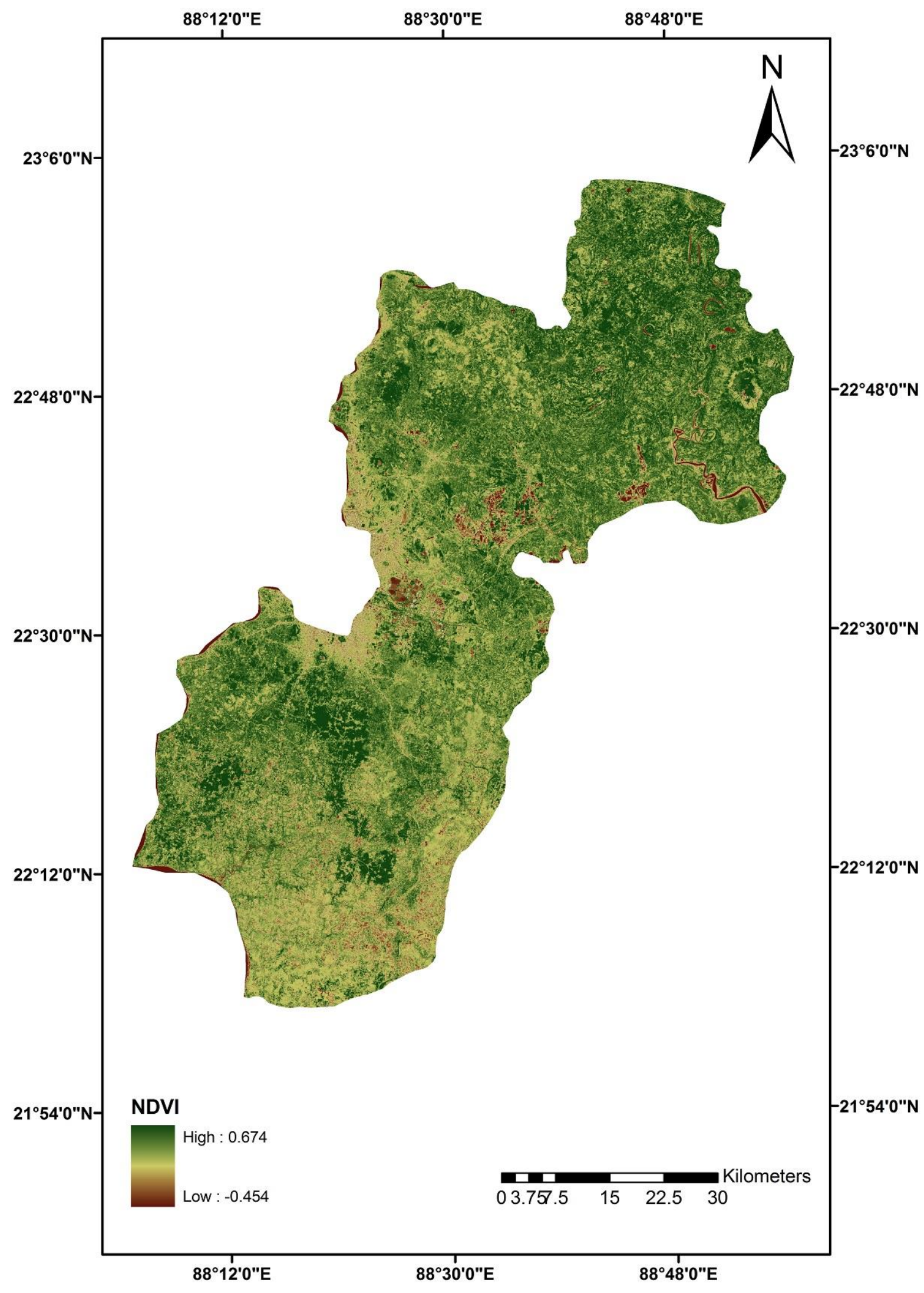

Fig. 7: Map Showing the NDVI of the Area. 


\section{Conclusion}

The mineral composition of the soil sample was analysed through band ratioing and X-Ray Diffraction method. Band ratioing method using Landsat imagery shows that the study area contains clay and ferrous minerals as the mineral composite. The result was further verified by the interpretation of XRD data which shows that the common minerals found in the soil samples are quartz, albite, augite, diopside, muscovite along with orthoclase/oligoclase, anhydrite, kyanite, microcline, calcite, epidote, dolomite and siderite. XRF analysis shows that soil sample contains most of the nutrients that are essential for the plant growth, except molybdenum. Principal component analysis shows that most of the elements present in the soil are derived from the weathering of the minerals present in the area. The good water holding capacity of the clay minerals and the essential elemental composition of the soil promotes the good vegetation growth that is evident from NDVI value as most of the area has vegetation and agriculture.

\section{Acknowledgement}

The first author acknowledges the University Grant Commission for providing fellowship during the tenure of $\mathrm{PhD}$. The author also acknowledges the Jawaharlal Nehru University, New Delhi for providing instrumentation facilities for conducting this work.

\section{References}

[1] Akalan I (1977) Toprak Olusu, Yap $1 \mathrm{~s} 1$ ve Ozellikleri (Ankara, TR: Ankara Universitesi, Ziraat Fakultesi Yayinları 662/204), pp. 342.

[2] Alloway BJ (1995a) Heavy Metals in Soils, 2nd edn. pp 368. Blackie Academic and Professional, London. ISBN 0-7514-0198-6. http://dx.doi.org/10.1007/978-94-011-1344-1.

[3] Bell RW \& Dell B (2008) Micronutrients for Sustainable Food, Feed, Fibre and Bioenergy Production. First edition, IFA, Paris, France.

[4] Campbell JB (1996) Introduction to Remote Sensing, 2nd edn. (New York-London: The Guilford Press), pp. 468.

[5] Cattell RB \& Jaspers J (1967) a general plasmode (no. 30-10-5-2) for factor analytic exercises and research. Multivariate Behavioral Research Monographs 67, 1-212.

[6] Coppin P, Jonckheere I, Nackaerts K \& Muys B (2004) A review: Digital change detection methods in ecosystem monitoring: a review. International Journal of Remote Sensing 25, 1565-1596. http://dx.doi.org/10.1080/0143116031000101675.

[7] Crosta AP \& Moore JM (1989) Enhancement of Landsat Thematic Mapper imagery for residual soil mapping in SW Minas Gerias state, Brazil: a prospecting case history in Greenstone belt terrain. Proceeding of the Ninth Thematic conference on Remote Sensing for Exploration Geology, Calgary, Alberta, Canada, 2-6 October, pp. 1173-1187.

[8] Darning WP (1998) Affiliated Research Center, Integrated Use of Remote Sensing and GIS for Mineral Exploration. Final Report, pp 3-4.

[9] Drury SA (1993) Image interpretation in Geology, 2, pp.145 - 149; pp. $225-231$.

[10] Elangovan D \& Chalakh ML (2006) Arsenic pollution in West Bengal. Technical Digest 9, 31-35.

[11] Ferrier G, Griffiths KWG, Bryant R \& StefoulI M (2002) The mapping of hydrothermal alteration zones on the island of Lesvos, Greece using an integrated remote sensing dataset. International Journal of Remote Sensing 23, 1-16. http://dx.doi.org/10.1080/01431160010003857.

[12] Goetz AFH \& Rowan LC (1981) Geologic remote-sensing. Science 211, 781-791. http://dx.doi.org/10.1126/science.211.4484.781.

[13] Grim RE (1962) Applied Clay Mineralogy (New York, Toronto, London: McGraw-Hill) pp. 422.

[14] Gupta RP (2003) Remote sensing Geology. 2nd edition, Springer, Germany. http://dx.doi.org/10.1007/978-3-662-05283-9.

[15] Holmgren GGS, Meye MW, Chaney RL \& Daniels RB (1993) Cadmium, lead, zinc, copper and nickel in agricultural soils of the United States of America. Journal for Environmental Quality 22,
$335-348$

http://dx.doi.org/10.2134/jeq1993.00472425002200020015x.

[16] Huang PM (1998) Soil Chemistry and Ecosystem Health, SSSA Special Publication Number 52. Soil Society of America, Madison, WI, USA, pp. 386.

[17] Jensen JR (1996) Introductory Digital Image Processing: A Remote Sensing Perspective, 2nd edn. (Englewood Cliffs, New Jersey: Prentice-Hall), pp. 316

[18] Khidir SOEl \& Babikir IAA (2013) Digital image processing and geospatial analysis of landsat 7 ETM+ for mineral exploration, Abidiya area, North Sudan. International Journal of Geomatics and Geosciences 3(3), 645-658.

[19] Lunetta RS, Knight JF, Ediriwickrema J, Lyon JG \& Worthy LD (2006) Land-cover change detection using multi-temporal MODIS NDVI data. Remote Sensing of the Environment 105, 142-154. http://dx.doi.org/10.1016/j.rse.2006.06.018.

[20] Mattigod SV \& Page AL (1983) Assessment of metal pollution in soils. Applied Environmental Geochemistry (ed. Thornton, I) Chap 12, pp. 355-394.

[21] Mazlum N, Ozer a \& Mazlum S (1996) Interpretation of water quality data by principal components analysis. Journal of Environmental Engineering Science 23, $19-26$.

[22] McLaren RG, Swift RS \& Quin BF (1984) EDTA-extractable copper, zinc, and manganese in soils of the Canterbury Plains. New Zealand Journal of Agricultural Research 27, 207-217. http://dx.doi.org/10.1080/00288233.1984.10430423.

[23] Meer FD van der, Werff HMA van der, Ruitenbeek FJA van, Hecker CA, Bakker WH, Noomen MF, Meijde M van der, Carranza EJM, Smeth JBde \& Woldai T (2012) Multi- and hyperspectral geologic remote sensing: A review. Interantional Journal of Applied Earth Observation and Geoinformation 14, 112-128. http://dx.doi.org/10.1016/j.jag.2011.08.002.

[24] Moore DM \& Reynolds RCJr (1997) X-Ray Diffraction and the Identification and Analysis of Clay Minerals (New York: Oxford University Press), pp. 378.

[25] Mortvedt JJ (1996) Heavy metal contaminants in inorganic and organic fertilizers. Fertility Research 43, 55-61. http://dx.doi.org/10.1007/BF00747683.

[26] Mshiu EE (2011) Landsat remote sensing data as an alternative approach for geological mapping in tanzania: a case study in the rungwe volcanic province, south-western tanzania. Tanzania Journal of Sciences 37, 26-36.

[27] Rowan C \& Lathram EH (1980) Mineral Exploration, Remote Sensing in Geology (Chapter 17) (B.S. Siegal and A.R. Gillespie, editors), John Wiley and Sons, New York, pp. 702.

[28] Sabins FF Jr (1987) Remote Sensing Principles and Interpretation, 2nd edn. (New York: W. H. Freeman \& Co).

[29] Vernet JP (1992) Impact of heavy metals on the environment. Series: trace metal in the environment. Elsevier Science, Amsterdam, pp. 444.

[30] Wolt J (1994) Soil solution chemistry: application to environmental science and Agriculture. Wiley, New York. 